\title{
How the hospitality industry reacts to COVID-19: structural, managerial and tactical factors
}

\author{
Claudio A. Piga ${ }^{1}$ - Graziano Abrate ${ }^{2}$. Giampaolo Viglia ${ }^{3,4} \cdot$ Francesca De Canio $^{5}$
}

Received: 28 July 2021 / Accepted: 4 November 2021 / Published online: 24 November 2021

(c) The Author(s), under exclusive licence to Springer Nature Limited 2021

\begin{abstract}
This paper investigates hoteliers' short-term recovery strategies during the pandemic. Stemming from management crisis theory and the resource-based view of the firm, this article focuses on two environments differently hit by COVID-19, i.e. London and Munich. The findings show that hotels with a more managerial approach have more proactively applied dynamic pricing strategies. When dealing with high severity levels of the pandemic, hoteliers make use of a more streamlined booking portfolio to cope with the crisis. We provide theoretical implications and actionable managerial levers for hoteliers and the wider pricing community on how to maximize revenues during the pandemic.
\end{abstract}

Keywords COVID-19 $\cdot$ Crisis management $\cdot$ Resource-based view $\cdot$ Short-term recovery strategies $\cdot$ Dynamic pricing · Booking tactics

\section{Introduction}

While other catastrophic events, such as a terrorist attack, usually affect a single specific geographic area and have no long-time effects on the sector (Zeng et al. 2005), pandemics-as the same word etymology suggests-are increasingly hitting global economies, making the hospitality sector particularly vulnerable (Alonso et al. 2020; Hao et al. 2020; Nicolaides et al. 2019; Sigala 2020). The number of travellers and overnight stays dropped, and occupancy rates went down as low as $6 \%$ in Rome and $11 \%$ in the USA and China in March 2020 (Nicola et al. 2020). Government measures to reduce the virus spread such as lockdowns, social distancing measures, borders' shutdown and other travel restrictions (Anderson et al. 2020) have contributed to reduce the tourism demand, negatively impacting on the hospitality sector. To cope with the unprecedented nature of COVID-19, governments and sport associations postponed to 2021 all

\footnotetext{
Graziano Abrate

graziano.abrate@uniupo.it

University of Genova, Genova, Italy

University of Piemonte Orientale, Vercelli, Italy

3 University of Portsmouth, Portsmouth, UK

4 University of Valle D'Aosta, Aosta, Italy

5 University of Modena and Reggio Emilia, Modena, Italy
}

mega events (e.g. Tokyo Olympic Games and EURO2020), affecting lodging demand and forcing a redesign of business plans in hospitality firms. Mega-sport events generally bring higher country image (Sun et al. 2013; Chen 2011), an increase in tourists' intake (Fourie and Santana-Gallego 2011) and some benefits for commercial activities and restaurants (Barreda et al. 2017). All this was lost (Nicola et al. 2020). The "so-called lasting legacies in the host cities or countries" (Fourie and Santana-Gallego 2011, p. 1364) turned into a sudden drop in demand and destination image with long-term repercussions on the hotel system. Thus, for example, the postponement of the EURO2020 football matches, across 12 cities in different countries, provoked an estimated revenue loss of 300 million euros (Statista 2020).

There are limited studies on the hospitality companies' response and recovery to crises when a pandemic is underway (Chen et al. 2020; Paraskevas et al. 2013; Ritchie and Jiang 2019). Revenue management, and the role it can play, has also been scarcely investigated, despite its adaptability to new business scenarios (Noone 2016). This article investigates the short-term recovery patterns adopted by hospitality operators facing the COVID-19 negative effects. Specifically, drawing from crisis management theory and the resource-based view of the firm, it evaluates the effect of COVID-19 on two European cities where the pandemic has hit with different degrees of severity (i.e. Munich and London). Within a context of great uncertainty and scarce 
demand, the adoption of dynamic pricing and/or booking tactical strategies becomes mandatory for hospitality operators (Abrate and Viglia 2016). The quasi-experimental design comprises of a full list of mid-scale to luxury hotels (i.e. $3^{*}, 4^{*}$ or $5^{*}$ establishments) in Munich and London, allowing to untangle how hotels reacted as various stages of the pandemic unfolded, relative to the pre-pandemic phase. We show different patterns depending on structural, managerial and tactical factors. Importantly, we show how hotels mix dynamic pricing strategies and product characteristics (i.e. free booking cancellation, "breakfast service included" option, number of people allowed in the room) to cope with the economic losses.

From a theoretical standpoint, applying the resourcebased view and the crisis management theory, the paper contributes by analysing the approach of the hospitality sector to a global pandemic. Further it contributes to the literature by empirically analysing hoteliers' context-related heterogeneous short-term recovery strategies. The focus revolves around the mix of dynamic pricing and other booking characteristics adopted by hoteliers located in areas hit differently by COVID-19. In doing so, the paper offers actionable advice to hoteliers affected by a different degree of severity of the pandemic.

\section{Theoretical background}

\section{The role of structural and managerial factors in coping with pandemics}

Crisis management theory in modern enterprises has its root in the work of Booth (2015). Relative to previous perspectives, this theory proposes a dynamic approach to crises so that companies can respond quickly under uncertainty. More recently, the emerging literature on crisis management in the hospitality sector has highlighted how the sector is highly susceptible and vulnerable to crises and disasters that dramatically alters the international tourism demand (Crò and Martins 2017; Morrish and Jones 2020; Ritchie and Jiang 2019; Sigala 2020). Sudden catastrophic events generate a state of uncertainty in the sector that can determine the ending or curtailment of hospitality activities (Ritchie and Jiang 2019). On the one hand, hospitality operators experience negative local and heterogeneous effects provoked by economic and political crises, terroristic activities and environment and weather disasters (Dahles and Susilowati 2015; Paraskevas et al. 2013). On the other hand, increasingly virulent pandemics negatively affect operators globally (Anderson et al. 2020). There is a reduction of the number of reservation (Gössling et al. 2020), with an impact on liquidity (Nicolaides et al. 2019) aggravated by national borders' shutdown (Hao et al. 2020).
Hospitality operators require a wide range of resources and capabilities, which, however, are heterogeneous across operators (Barney 1991). A high/low control and coordination of resources and capabilities, usually associated with hotel's organizational forms, brings to different hotel performance (Revilla-Camacho et al. 2020). Thus, structural resources may support a prompt response to the negative event and the ensuing economic losses. To limit the damage of crises at both organization and destination level and to recover from direct and indirect impacts of the catastrophic event, operators need to adopt urgent and emergency tactical actions (Ritchie and Jiang 2019) mainly based on intangible knowledge capital exemplified in the firm's resources and capabilities (Barney 1991; Paraskevas et al. 2013). A more reactive strategy depends on the structural presence of the necessary resources and capabilities to face the crisis. On the one hand, the managerial ability to provide a flexible response to cope with the uncertainty of a sudden crisis is key in the resource-based view of the firm. Specifically, the ability to promptly mix the available resources based on the changed market context may reduce crises' negativities (Köseoglu et al. 2020). The effective pandemic response plans developed by Chinese hotels, based on the anti-SARS experience, are an example (Hao et al. 2020). On the other hand, the use of temporary price reduction and a wise use of the dynamic pricing may protect revenues. The role of pricing as a capability which is underpinned by organizational routines and processes (Dutta et al. 2002, 2003; Makadok 2001), suggests that it might be more intensively used as a crisis management tool in hotels endowed with other complementary resources and capabilities.

H1a Compared to the pre-pandemic period, price differentials are more contingent on the structural hotel conditions.

H1b Compared to the pre-pandemic period, hotels with a more managerial approach to revenue management make a higher use of dynamic pricing strategies.

\section{Proactive crisis response: dynamic pricing and booking tactics}

Sigala (2020) underlined how pricing strategies and new booking strategies can be an effective way to deal with the crisis. As clarified in the dynamic approach of crisis management theory (Booth 2015), strategies should be flexible and shaped on the severity of the crisis (Osiyevskyy et al. 2020), as well as aimed at achieving objectives that may vary depending on its main customers' basis (Pohland and Kesgin 2018). Dynamic pricing strategies have "the capacity to withstand turbulence and bounce back from disruptions" (Dahles and Susilowati 2015, p. 35). The use of dynamic pricing strategies is an effective way to manage peaks and 
voids, seasonality, customers' needs and hotels' occupancy rate. That is why dynamic pricing is increasingly used in the tourism and hospitality domain (Abrate and Viglia 2016). The main outcome from the use of dynamic pricing is the presence of time-sensitive differential prices to diverse market segments (Cross et al. 2009), generating both higher hotels' revenues and customer satisfaction (Ye et al. 2019). The spread of the Internet and the use of pricing software packages have fostered the adoption of dynamic pricing (Abrate and Viglia 2016). Online tools-by which hotels can easily adjust prices in real time depending on the number of available rooms, prices of close competitors and other contextual indicators (Viglia et al. 2016) — have facilitated the practice of dynamic pricing. Further, the widespread usage of online travel agencies (OTAs) such as Booking.com, have made the use of dynamic pricing even more relevant and personalized. OTAs provide hotels with important analytics, favouring real-time price adjustments (Inversini and Masiero 2014). As showed by Oaten et al. (2015), the use of dynamic pricing is essential to cope with disasters and recovery programs. Its flexibility makes dynamic pricing strategies to be the baseline approach to face the pandemic.

Another opportunity for hoteliers during the pandemic is the adoption of new booking patterns (Sigala 2020). Indeed, the continued cooperation with online intermediaries guarantees that a sudden drop in demand can be compensated by a wider portfolio of extra-core services. Apart from prices, hoteliers can exert other possible tactical reactions using extra-core services. Thus, offering several booking options may be a lever to attract customers and stimulate demand. By assuming the risk caused by crises, hoteliers can be more attractive with positive returns on the occupation rate and on the long-term financial performance (Morrish and Jones 2020). Hotels can allow for extra booking options, such as offering the free cancellation option (Chen et al. 2011), breakfast (or not) (Guizzardi et al. 2017) and post (or not) the room for single or multiple customers.

The underlying theory of crisis management (Booth 2015) explains that different levels of severity require different solutions. When facing crises with high level of severity, opting for reduced set of strategies leads to higher performance. On the contrary when the impact of the crisis decreases, a wider variability in the offer leads to increased performances (Osiyevskyy et al. 2020).

H2a Compared to the pre-pandemic period, the price differentials between a no-frill reservation and a reservation including additional attributes (i.e. free cancellation, breakfast included and multiple booking options) increase.

H2b When dealing with high severity levels of the pandemic, hoteliers will make use of a more optimized (streamlined) booking portfolio to cope with the crisis.
Table 1 presents an overview on how hoteliers coped with different types of crises in the past. A flexible management of resources and capabilities supports a prompt response to crises (Hao et al. 2020). Marketing tools and a wide offer of extra services improve the brand image and support bookings (del Mar Alonso-Almeida and Bremser 2013; Page et al. 2006). Additionally, dynamic pricing strategies support the resumption of demand, boosting the occupancy rate and the sector occupation (Chen 2011; Oaten et al. 2015; Tew et al. 2008).

\section{Method}

\section{Data collection and the quasi-experiment setting}

The analysis takes advantage of a unique dataset monitoring the evolution of the prices and room characteristics. The data collection started well before the diffusion of COVID19 (October 2019). Therefore, the type of data configures a quasi-experimental setting. This allows studying hotel tactical reactions to such an unpredictable event, which also led to the postponement of an important event, i.e. the European football tournament (EURO 2020).

The data collection involved four steps. First, we obtained the full list of establishments listed as hotels in Booking.com for two cities where the event was due to take place (Munich in Germany and London in the United Kingdom). For each establishment, we obtained its unique url identifier.

Second, using the url identifier, we scraped the pages of all hotels, retrieving the star classification and whether the hotels are affiliated with a chain or not. We stratified the sample so to keep hotels with at least a three-stars classification, as evidence indicates that hotels with lower stars exhibit a very low propensity toward dynamic pricing (Melis and Piga 2017). With respect to previous similar data collections (e.g.Abrate et al. 2019; Nicolini and Piga 2019), a new feature is the extraction of data from the hotels' specific site on the OTA. Doing so allows more data to be retrieved relative to those available from the listings based on a city identifier. More specifically, the hotel page contains prices for all the rooms offered on a specific query date, including a precise definition of the offer characteristics in terms of cancellation policy, breakfast inclusion and the number of persons allowed. Finally, room prices were retrieved in the currency of the city's nation: this avoids spurious price differences induced by the Booking.com's currency converter.

Third, we defined the following period of stay dates: 8th June-9th July. In each city, these include some days before the start of the tournament, all match days, the day before and after each match, and some days during the tournament period. Starting on October 18th 2019, 
Table 1 How the hospitality industry reacted to past crises

\begin{tabular}{ll}
\hline Paper & Crisis Event \\
\hline Chen (2011) & $\begin{array}{l}\text { Taiwan's hotel response to the 9/21 earth- } \\
\text { quake, 11/9 terrorist attack and SARS } \\
\text { outbreak }\end{array}$
\end{tabular}

Findings

Chien and Law (2003) SARS outbreak in Hong Kong

del Mar Alonso-Almeida Economic crisis in Spain and Bremser (2013)

Hao et al. (2020)

COVID-19

Henderson and $\mathrm{Ng}$ (2004) SARS outbreak in Singapore

Morrish and Jones (2020) Earthquake in New Zealand

Oaten et al. (2015) Economic shock and Terrorist attack

Page et al. (2006) Avian Influenza

Tew et al. (2008)

SARS Outbreak in Toronto (Canada)
Analysing through panel data techniques a set of hotels in Taiwan, the author found that hotels had to reduce prices significantly to support inbound tourism. The Taiwanese Government proactively helped operators to face the crisis by the means of two promotional measures: Doubling Tourist Arrival Plan, implemented in 2002, to attract 5 million international tourists and the Tourism Flagship Plan, implemented in 2005, to promote local attractions and cultural events

To cope with the spread of the outbreak illness, hoteliers provided additional cleaning and established task forces administered by the General Manager. This favoured the collection of different information and concerns

Hotels that increased their quality standards and consequently their brand image were able to better handle the crisis

Applying the management crisis theory to Chinese hotels timely responding to the Covid-19 pandemics thanks to the resources and capabilities implemented after the SARS experience, bounced forward the crisis implementing innovative and flexible solutions

After the mass cancellation due to the SARS outbreak, hoteliers turned their offer to residents and devised promotional packages for this target group

The paper identifies four main strategies to cope with the disaster: (i) organize resource, (ii) accept risk, (iii) create new value for customers and (v) seek for opportunities

Analysing hotel market resilience to uncertainty due to crises, the authors found that hoteliers applied discounted prices to secure bookings during these economic shocks. Discounts helped to increase occupancy rates significantly

All accommodation formats suffered a sudden drop in demand. Due to the reduced travel from South-East Asia, Australia and New Zealand, marketing efforts were directed to attract pan-European and the domestic market

After the SARS outbreak in Toronto, almost $60 \%$ of hotels offered discount packages to boost hotel occupancy. In the recovery stage, hotels cooperated with associations and governments to recover reputation and tourism demand. Associations and governments developed touristic plans aimed at promoting Toronto as a viable travel option



Fig. 1 Timeline of events and data collection 
and continuing with a frequency of three days, data were scraped during the period ahead of the tournament start.

From the second half of March 2020, when the COVID19 crisis began to spread across Europe, the data collection assumed a daily frequency, to allow a day-to-day evaluation of the hotels' changes in the pricing of the same stay dates. On March 17, the UEFA announced its decision to postpone the event by 1 year. The data collection ended on June 5, just a week before the planned start of the cancelled tournament.

Figure 1 summarizes the most significant events during the time of data collection and defines the basis to investigate the tactical response of hotels.

To define the two baseline experimental conditions, we divided the booking window in a pre- and post-lockdown period. We preferred to use the same date (March 22) as the breakdown of the dataset for two reasons. First, the postponement of Euro 2020 clearly affected both cities at the same time. Second, despite early political response to pandemic was lagged in the UK with respect to Germany, the strictest enforcements were introduced almost simultaneously (Hall 2020). Lockdown started in Germany on March 22, while the UK's Prime Minister Speech (2020) announced the lockdown measures on March 23.

Then, we further divided each of the experimental conditions (pre- and post-) into two sub-periods. In the prelockdown condition, it is interesting to see whether the hotels were able to anticipate the reaction following the early signals of the pandemic risk. While COVID-19 was present since January and had already peaked its diffusion in China, in Europe the risk became more concrete when Italy put in lockdown 11 towns on February 23 (Giuffrida and Cochrane 2020). Thus, the occurrence of this event was set to classify the online search dates into two sub-periods: business as usual (BAU, before February 23) and early pandemic (EARLY, from February 23).

As to the analysis of the post-lockdown period in London and Munich, one must first consider that the UK was more harshly hit by the first wave of COVID-19, with the number of daily deaths (on a weekly basis) peaking close to 1000 , compared to less than 250 in Germany. As documented in details by the ECDC (European Centre for Disease Prevention and Control), this reflected on different duration and severity of restrictions (https://covid19-country-overviews. ecdc.europa.eu/). From late April, Germany progressively started to relax the lockdown, allowing at least a partial reopening of non-essential shops (20th April), followed by primary and secondary schools, entertainment venues and restaurant and cafes (May 10). On the contrary, in the UK, a partial reopening of non-essential shops started from May 10 , but primary schools remained fully closed until the end of May and secondary schools until June 14. Moreover, the UK did not open entertainment venues as well as restaurant and cafes until July 4. Coherently with Han et al. (2020), the date of May 1 might be considered a cut-off for substantial easing of restrictions in Germany, one month ahead with respect to the UK. As this lag should have engendered higher hotel recovery expectations in Germany rather than in the $\mathrm{UK}$, we classified the post-lockdown online search dates into two sub-periods: pandemic peak (PEAK, before 1st May), and easing of restrictions (EASING, after May 1).

Table 2 summarizes the definition of the different periods of observations.

Table 2 Definition of experimental conditions

\begin{tabular}{|c|c|c|c|c|}
\hline \multirow[t]{3}{*}{ Baseline setting } & \multicolumn{2}{|l|}{ Period 1: Pre-Lockdown (PRE) } & \multicolumn{2}{|c|}{ Period 2: Post-Lockdown (POST) } \\
\hline & \multicolumn{2}{|l|}{ 18th October-21st March } & \multicolumn{2}{|l|}{ 22nd March-5th June } \\
\hline & \multicolumn{2}{|l|}{ Base condition } & \multicolumn{2}{|c|}{$\begin{array}{l}\text { Detect the main effect due to lockdown and event cancel- } \\
\text { lation }\end{array}$} \\
\hline \multirow[t]{3}{*}{ Further breakdown } & 18th October-22nd February & 23rd February-21st March & 22nd March-30th April & 1st May-5th June \\
\hline & $\begin{array}{l}\text { Period 1a: Business as usual } \\
\qquad(B A U)\end{array}$ & $\begin{array}{l}\text { Period 1b: Early Pandemic } \\
\quad(E A R L Y)\end{array}$ & $\begin{array}{l}\text { Period 2a: Pandemic Peak } \\
\quad(P E A K)\end{array}$ & $\begin{array}{l}\text { Period 2b: Easing of restric- } \\
\text { tions }(E A S I N G)\end{array}$ \\
\hline & Define typical hotel strategies & $\begin{array}{l}\text { Growing uncertainty and } \\
\text { early hotel reactions }\end{array}$ & $\begin{array}{l}\text { Both cities (Munich and } \\
\text { London) under strict } \\
\text { restrictions }\end{array}$ & $\begin{array}{l}\text { Easing of restrictions } \\
\text { with different degrees in } \\
\text { Munich and London }\end{array}$ \\
\hline
\end{tabular}




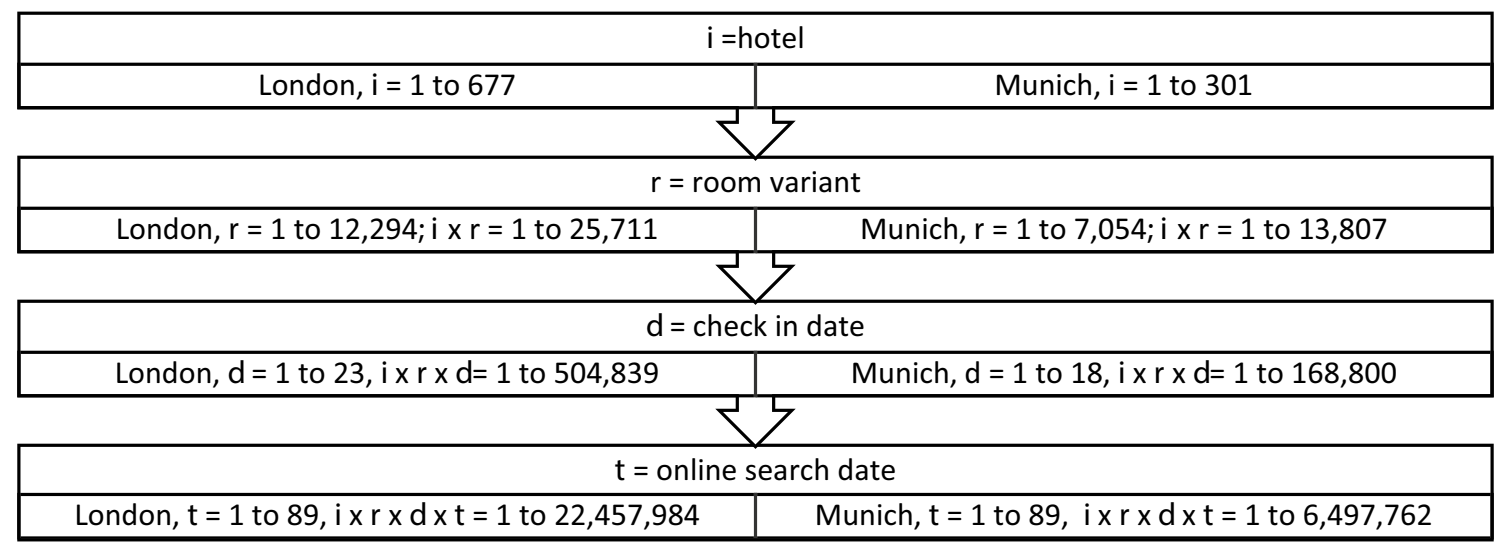

Fig. 2 Composition of the dataset and number of observations in London and Munich

\section{The empirical model}

The empirical analysis revolves around an unbalanced multidimensional panel data. Let $i$ identify the hotel, $r$ the specific variant of room posted (e.g. a standard double room with free cancellation and with breakfast included), $d$ the checkin date (from June 8 to July 9) and $t$ the online search date (from 18th October 2019 to 5th June 2020). The combination of these four levels of information defines the raw unit of observation for the price posted $\left(P_{i r d t}\right)$. Figure 2 clarifies the structure of the dataset presenting the number of observations in each dimension, up to a total of more than 22.5 million in London and 6.5 million in Munich.

The empirical strategy follows two steps. The first step (Eq. 1) investigates the determinants of price over the online search dates, as identified above, using a fixed effect specification at the level of each hotel, room variant and check-in date $\left(u_{i r d}\right)$. The dependent variable has been transformed in logarithm, as usual in similar studies, to facilitate comparison of percentage changes across cities. The advantage of including such fixed effects is to detect real changes in the price posted by a hotel regarding a specific item, thus excluding the risk of attributing a price change to a change in the product characteristics. scope is to estimate the way hotel characteristics affected price changes due to the pandemics, rather than price levels (the latter, anyway, are absorbed by the fixed effects).

HotelType includes characteristics such as the number of stars (3,4 or 5) and being part of a chain, as well as two additional criteria to cluster hotels. These criteria derive from monitoring the hotel pricing strategy in the preCOVID period (in particular, in the $B A U$ period as defined in Table 2), with reference to the management of bookings for a high-demand condition generated by the EURO2020 event.

Dynamic hotels The first criterion aimed at identifying those hotels who are more active in terms of revenue management within the booking.com channel. Abrate et al. (2019) showed that hotels applying more price variability through the booking window are likely to obtain better revenue performance. To this aim, we monitored price changes over the search period with respect to uniquely identified room variants, coherently with the idea of detecting "true" price changes (changes to or from missing are counted as changes too). Then, we defined as "Dynamic" those hotels who were changing prices more than the average in the pre-COVID period.

OTA-independent hotels The second criterion wants to

$\ln P_{\text {irdt }}=f\left(\right.$ Period $_{t} ;$ Period $_{t} \times$ HotelType $_{r} ;$ Period $_{t} \times$ RoomType $\left._{i} ; \beta\right)+u_{\text {ird }}+v_{\text {ird } t}$

In Model 1, $\beta$ identifies the vector of parameters to estimate, while $v$ is the classical white noise. Coherently with Table 2 , Period classifies the online search dates into either a dummy variable ("Pre-Lockdown", $P R E$ vs. "Post-Lockdown", POST) or a multi-period category (BAU, EARLY, PEAK, EASING). Apart from identifying an average change in the price offers, Period interacts with HotelType, which is a vector of establishment characteristics. The inclusion of such interaction specifically aims at verifying hypotheses $\mathrm{H} 1 \mathrm{a}$ and $\mathrm{H} 1 \mathrm{~b}$, in that the capture the hotels that are presumably less dependent from the OTA (Stangl et al. 2016). Dependency from booking.com is a common issue in European hotels, and a reduction of such dependency is often advocated as a strategy of primary importance (Mellinas 2019). To build a proxy for this situation, we argue that those hotels selling a significant portion of their rooms through direct bookings or other channels could more actively rationalize their supply on Booking.com, particularly in the case 
of high-demand check-in dates such as the ones analysed in the current study corresponding to when a match is scheduled. On the contrary, those hotels relying mostly on Booking.com could not benefit much from this type of strategic unavailability, which has been shown to significantly affect revenues (Abrate et al. 2019). Accordingly, the dummy variable classifying OTA-independent hotels is set to 1 when those hotels did not post any room rates in Booking.com for at least 60 consecutive days, for at least one specific check-in date, generally coinciding with a match date; otherwise, the variable is set to 0 .

In addition, Period interacts with RoomType, a vector of variables describing specific room attributes, such as free cancellation, inclusion of breakfast and the number of guests allowed (up to 2 persons or more). This interaction captures the way the pandemics has eventually changed the price premium attributed to each of these room attributes, thus responding to $\mathrm{H} 2 \mathrm{a}$.

The second step of the analysis looks more in details at the variety of price offers and provides the field for the empirical verification of $\mathrm{H} 2 \mathrm{~b}$. The unit of exploration moves at the hotel level. A number of indicators is used to describe the menu of pricing posted by a hotel during a specific date search. These are chosen considering that a proactive response to the crisis should exploit the synergy between pricing and the customer service induced by the new conditions (Haynes 2016).

- The number of available options posted, as a proxy of variety $(V A R)$.

- The share of Free Cancellation offers over the total number of options posted $\left(S H A R E_{F C}\right)$.

- The share of options posted with "breakfast included" $\left(S_{H A R E} E_{B R}\right.$ ).

- The share of options posted and aimed to more than two persons $\left(S H A R E_{M P}\right)$.

The way these indicators change over the booking window might signal the quality of tactical reaction of hotels during the crisis, and a change in the objectives associated to pricing (Pohland and Kesgin 2018). For example, with the increased uncertainty, the free cancellation option is expected to be more widespread to reassure the clients in their booking process. By the same token, it could be expected that a proactive hotel is more likely to reduce the number of offers with more than two people, especially if inclusive of breakfast, as this may make it more difficult to satisfy social distancing measures.
Equation 2 describes the model which follows the same logic of interaction between Period and hotel characteristics, but the panel dimension is now reduced at the number of hotels $i \times$ the number of date search $t$.

\section{Results}

\section{Impact on price levels}

Table 3 presents the estimates of Eq. (1), obtained from a fixed-effects regression model where a cross-sectional unit corresponds to each hotel, room variant and check-in date, and the time dimension corresponds to the online search data. Table 3 facilitates the comparison between London and Munich, and the last column directly links the results on specific coefficients with the theoretical hypotheses. The coefficients associated to the post-lockdown approximate the average percentage price drops for rooms without free cancellation, without breakfast, for maximum 2 persons, in 3 -stars hotels not belonging to a chain and neither OTAindependent or dynamic $(-19.2 \%$ in London and $-32.5 \%$ in Munich). Thus, as expected, drops are significant in both cities. The sharper effect in Munich might seem counterintuitive given that Germany was not hit as badly as the UK; however, the drop cancels out the price premium due to the scheduled EURO2020 event, likely to be bigger in relatively smaller destinations. Moreover, the interest of the analysis is especially on the differential impact of each room and hotel attribute.

When comparing the effect of lockdown across different types of hotels, there are at least two important and counteracting forces driving price changes. On the one hand, the negative impact of the crisis is expected to amplify the price gaps due to structural conditions in the establishment (such as star levels) and in the competitive arena (such as the dependence/independence from OTA). In partial support of this hypothesis (H1a), findings show that $5^{*}$ hotels (at least in London), as well as OTA-independent (in both cities), because of better facilities or alternative channels, significantly retain a higher price premium with respect to the other establishments. On the other hand, more proactive hotels might react more promptly to preserve occupancy and RevPar (revenue per available room) performance, and to this end tactical revenue management suggest the need of sharper price reductions. Thus, H1b predicts that prices in hotels with a more effective and managerial approach to

$I_{i t}=g\left(\right.$ Period $_{t} ;$ Period $_{t} \times$ HotelType $\left._{i} ; \beta\right)+u_{i}+v_{i t}$ with $I=\left\{\right.$ VAR, SHARE $_{F C}, \operatorname{SHARE}_{B R}$, SHARE $\left._{M P}\right\}$ 
Table 3 Determinants of price changes after the lockdown

\begin{tabular}{|c|c|c|c|c|}
\hline \multirow{2}{*}{$\begin{array}{l}\text { VARIABLES } \\
\text { POST (Post-Lockdown) }{ }^{(1)}\end{array}$} & \multirow{2}{*}{$\begin{array}{l}\text { LONDON } \\
\text { Dep. var }=\ln \mathrm{P} \\
-0.192 * * * \\
(0.0191)\end{array}$} & \multirow{2}{*}{$\begin{array}{l}\text { MUNInCH } \\
\text { Dep. var. }=\ln P \\
-0.325^{* * *} \\
(0.0252)\end{array}$} & \multicolumn{2}{|c|}{$\begin{array}{l}\text { Expected sign and hypotheses } \\
\text { verification }\end{array}$} \\
\hline & & & & \\
\hline \multicolumn{5}{|l|}{ Period $\times$ HotelType } \\
\hline$P O S T \times 4$ Star & $\begin{array}{l}-0.00612 \\
(0.0211)\end{array}$ & $\begin{array}{l}-0.0234 \\
(0.0226)\end{array}$ & H1a: + & Not confirmed \\
\hline$P O S T \times 5$ Star & $\begin{array}{l}0.0490 * * \\
(0.0215)\end{array}$ & $\begin{array}{l}0.0483 \\
(0.0392)\end{array}$ & H1a: + & Partially confirmed \\
\hline$P O S T \times$ OTA-independent & $\begin{array}{l}0.0289 * \\
(0.0169)\end{array}$ & $\begin{array}{l}0.0477 * * \\
(0.0229)\end{array}$ & H1a: + & Confirmed \\
\hline$P O S T \times$ Chain & $\begin{array}{l}-0.0911 * * * \\
(0.0165)\end{array}$ & $\begin{array}{l}-0.0788 * * * \\
(0.0218)\end{array}$ & H1b: - & Confirmed \\
\hline$P O S T \times$ Dynamic & $\begin{array}{l}-0.0476 * * * \\
(0.0166)\end{array}$ & $\begin{array}{l}-0.0277 \\
(0.0211)\end{array}$ & H1b: - & Partially confirmed \\
\hline \multicolumn{5}{|l|}{ Period $\times$ RoomType } \\
\hline$P O S T \times$ Free Cancellation & $\begin{array}{l}-0.00171 \\
(0.00822)\end{array}$ & $\begin{array}{l}0.0807 * * * \\
(0.0114)\end{array}$ & $\mathrm{H} 2 \mathrm{a}:+$ & Partially confirmed \\
\hline$P O S T \times$ Breakfast & $\begin{array}{l}0.0221 * * * \\
(0.00680)\end{array}$ & $\begin{array}{l}0.0434 * * * \\
(0.0101)\end{array}$ & $\mathrm{H} 2 \mathrm{a}:+$ & Confirmed \\
\hline$P O S T \times$ More than 2 persons & $\begin{array}{l}0.0302 * * * \\
(0.00763)\end{array}$ & $\begin{array}{l}0.0215 \\
(0.0135)\end{array}$ & $\mathrm{H} 2 \mathrm{a}:+$ & Partially confirmed \\
\hline Constant & $\begin{array}{l}5.725 * * * \\
(0.00362)\end{array}$ & $\begin{array}{l}5.313 * * * \\
(0.00527)\end{array}$ & & \\
\hline Observations & $22,457,984$ & $6,497,762$ & & \\
\hline $\begin{array}{l}\text { Number of groups }(\text { hotel } \times \text { room } \\
\text { variant } \times \text { check-in date })\end{array}$ & 504,839 & 168,800 & & \\
\hline$R$ squared & 0.951 & 0.899 & & \\
\hline
\end{tabular}

Fixed-effects regression, with each cross-sectional unit defined as a specific hotel product (i.e. hotel $\times$ room variant $\times$ check-in date)

Robust standard errors in parentheses (clustered by hotels)

${ }^{(1)}$ POST is a dummy variable with value 1 when the online search date falls in the post-lockdown period, i.e. from 22nd March 2020

$\times$ denotes variables' interaction

$* * * p<0.01, * * p<0.05, * p<0.1$

revenue management should highlight a negative sign in the interaction with the post-pandemic period. Clearly, an objective proof of such relationship would require specific data about hotel management practices. However, this hypothesis finds support in that price reductions are significantly more consistent in two groups of hotels: chains, which may be associated to better skills and advantages in revenue management practices (Hollenbeck 2017), and dynamic hotels, which already showed a higher price variability in the prepandemic period.

As to the impact of lockdown on the price of different room variants, overall, there is a significant support to $\mathrm{H} 2 \mathrm{a}$. First, the sign of free cancellation is significant and positive in Munich. This means that the price fall for offers including free cancellation is significantly lower and is justified considering the higher value clients can attach to this option, especially in a period with increasing uncertainty. However, this effect does not emerge in London, where price drops distribute more uniformly across room variants. The inclusion of breakfast is a second factor mitigating the price drop, this time both in London and in Munich. If the effect of free cancellation might be justified from a value-based perspective, in the case of breakfast the increased differential with respect to basic accommodation offers probably stems from higher cost of managing this service due to COVID-19 related restrictions. In a similar perspective, rooms targeted to more than 2 people show a less pronounced price drop, though this effect is statistically significant only in London.

Figure 3 provides a focus on the predicted price drops in Munich and London according to the type of room, combining the free cancellation and breakfast options. The estimates are derived from predicted values of Model 
Fig. 3 Posted rates by room characteristics during pre- and post-lockdown periods. Note 1. Periods: BAU (Business as usual, 18/10 to 22/2); EARLY (Early pandemic, 23/2 to 21/3); PEAK (Pandemic peak, 22/3 to $30 / 4$ ); EASING (Easing of restrictions, 01/05 to 05/06). Note 2. Canc (Free cancellation: $1=$ yes; $0=$ no); Brkfst (Breakfast included: $1=$ yes; $0=$ no)
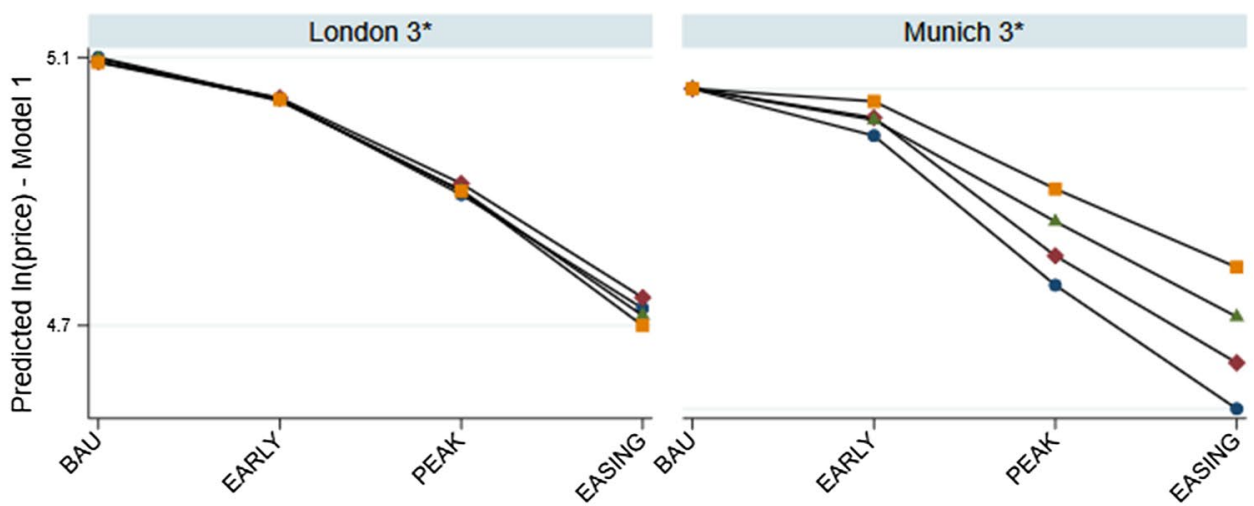

Pre-Post Lockdown Periods

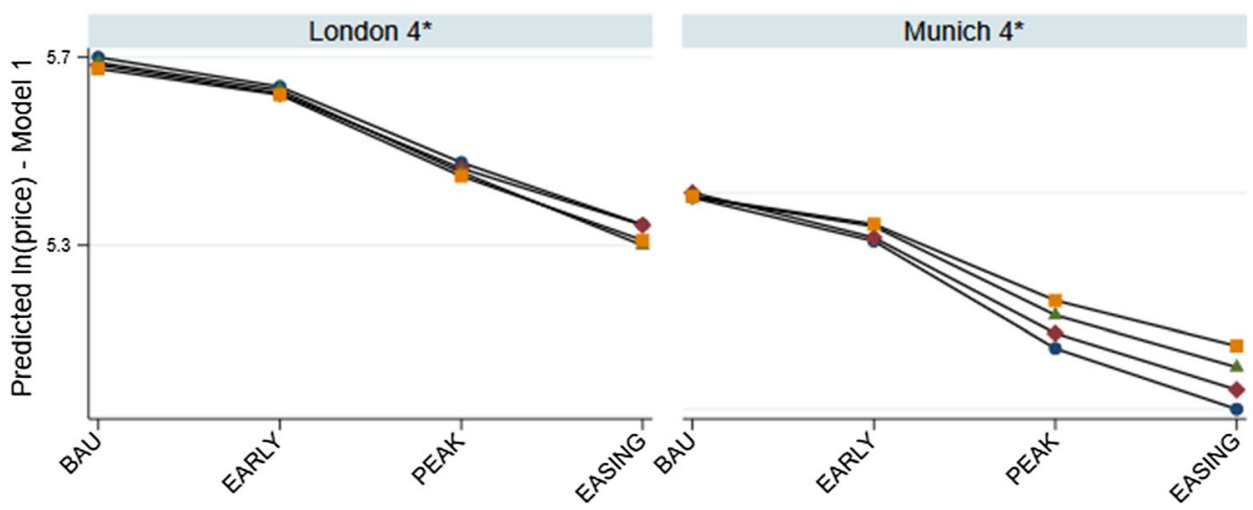

Pre-Post Lockdown Periods



don $5^{*}$

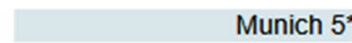

Munich $5^{*}$

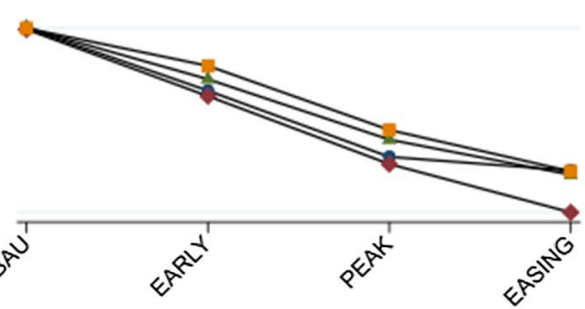

Pre-Post Lockdown Periods

Canc $=0$, Brkfst $=0 \longrightarrow$ Canc $=0$, Brkfst $=1$

Canc $=1$, Brkfst $=0 \quad \longrightarrow$ Canc $=1$, Brkfst $=1$
[1] modified to account for 4 time periods (BAU, EARLY, $P E A K, E A S I N G)$ and additional interacted terms for room characteristics and hotel characteristics (for sake of parsimony, the full set of coefficients is not presented but is available upon request). Interestingly, prices started going down already in the pre-lockdown period, probably because hotels started to cope with a reduced number of new bookings. Moreover, the picture makes it even more evident how the hotels in Munich discriminated more their price decreases by room characteristics, since the beginning of the crisis. In London, the price drops are similar and only after May 1 it is possible to see some significant divergence, especially for the breakfast option and in the case of $5^{*}$ hotels.

Figure 4 plots the evolution of predicted prices by hotel characteristics, following the same logic of Fig. 3 and focusing on the combination of the groups of OTA-independent and dynamic ones. It shows that dynamic hotels not only adjust prices more, but also react more quickly, a pattern substantially confirmed across all plots. However, 
Fig. 4 Posted rates by hotel characteristics during pre- and post-lockdown periods. Note 1. Periods: BAU (Business as usual, 18/10 to 22/2); EARLY (Early pandemic, 23/2 to 21/3); PEAK (Pandemic peak, 22/3 to $30 / 4$ ); EASING (Easing of restrictions, 01/05 to 05/06). Note 2. OTAi (OTA_independent: $1=$ yes; $0=$ no); Dyn (Dynamic: $1=$ yes; $0=$ no)
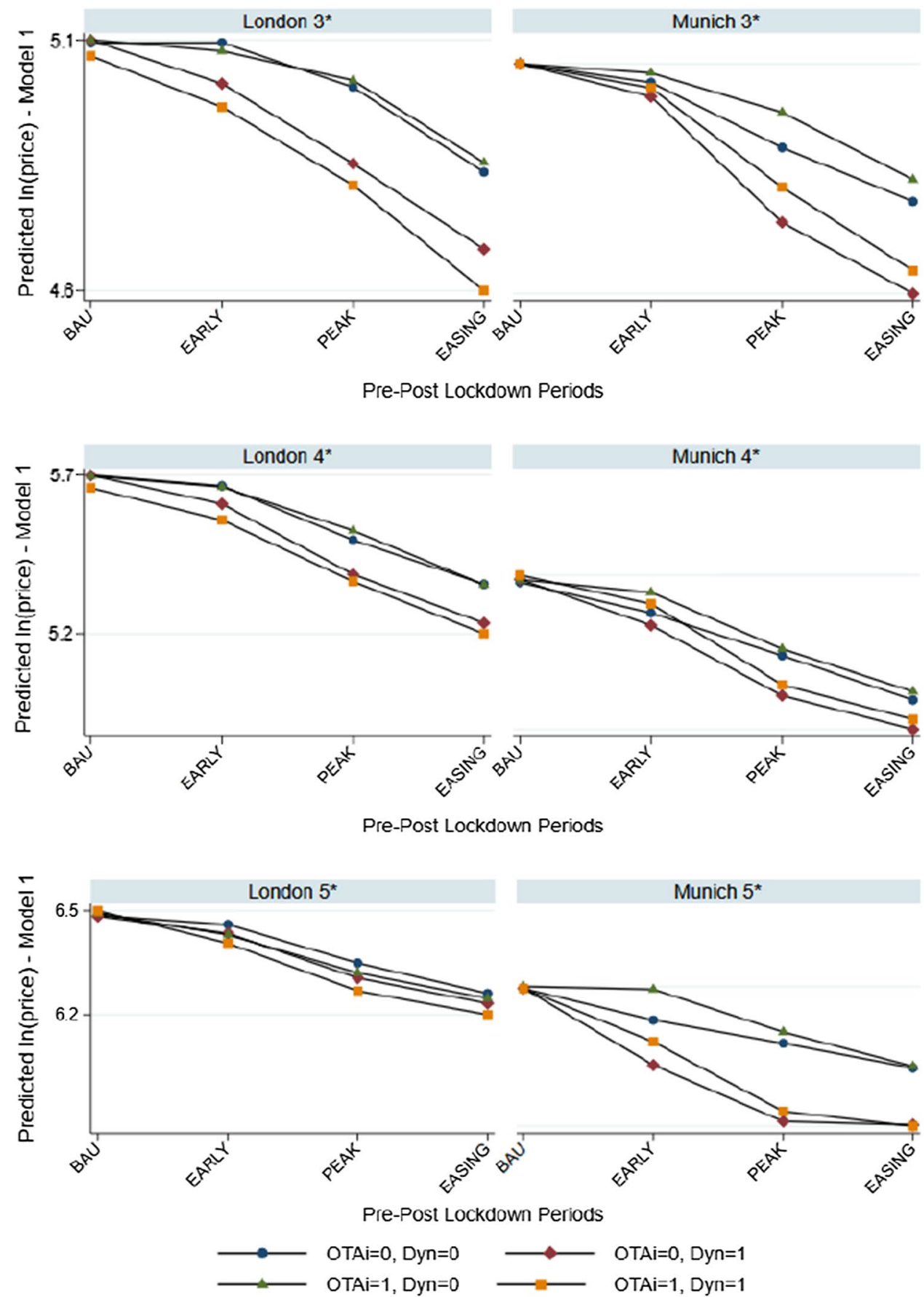

while the most reactive in London is the couple "dynamic \& OTA-independent", in Munich the most reactive is the couple "dynamic \& OTA-dependent". In addition, differently from London, in Munich the reducing trend become less evident from May 1, especially for dynamic hotels (in the case of $5^{*}$ dynamic hotels, the trend is almost flattened). This could represent a first attempt to react to the removal of some restrictions in Germany, even if the behaviour across hotels remained very heterogeneous.

\section{Impact on variety of supply}

The second step of the empirical analysis involves the estimation of Model [2], to understand the evolution of room variants over time. Findings of the first step have confirmed, at least partially, a higher value associated to the free cancellation option, to the inclusion of breakfast and rooms for more guests. Instead, Model [2] aims at verifying if hotels have been proactive in optimizing their booking portfolio in the post-pandemic period, thus reducing the variety of 
Table 4 Determinants of the variety of supply after the lockdown

\begin{tabular}{|c|c|c|c|c|c|c|c|c|}
\hline \multirow[b]{2}{*}{ VARIABLES } & \multicolumn{2}{|c|}{ VAR } & \multicolumn{2}{|c|}{ SHARE $_{\mathrm{FC}}$} & \multicolumn{2}{|c|}{ SHARE $_{B R}$} & \multicolumn{2}{|c|}{$S H A R E_{M P}$} \\
\hline & London & Munich & London & Munich & London & Munich & London & Munich \\
\hline \multirow[t]{2}{*}{ POST } & 0.877 & -0.981 & $4.459 * * *$ & 1.402 & $-4.715 * * *$ & -2.395 & -0.363 & 0.335 \\
\hline & $(0.571)$ & (1.139) & (1.309) & $(1.775)$ & $(1.245)$ & $(1.675)$ & $(0.282)$ & $(0.412)$ \\
\hline \multirow[t]{2}{*}{$P O S T \times 4$ Stars } & $-2.500^{* * *}$ & $-4.080^{* * *}$ & $2.788^{*}$ & -0.583 & $3.474 * * *$ & 0.0180 & $0.891 * * *$ & -0.174 \\
\hline & $(0.664)$ & $(1.176)$ & $(1.610)$ & (1.617) & (1.335) & $(1.575)$ & $(0.304)$ & $(0.404)$ \\
\hline \multirow[t]{2}{*}{$P O S T \times 5$ Stars } & $-2.844 * * *$ & -8.693 & 0.786 & 0.362 & $6.120 * * *$ & 1.999 & 0.246 & $-1.237^{*}$ \\
\hline & $(1.075)$ & $(5.314)$ & (1.888) & $(4.395)$ & (1.399) & $(2.692)$ & $(0.428)$ & $(0.665)$ \\
\hline \multirow[t]{2}{*}{$P O S T \times$ Chain } & $-2.615^{* * *}$ & $-3.067^{* *}$ & $9.690 * * *$ & $8.076^{* * *}$ & $2.312^{* *}$ & 0.749 & -0.170 & $1.004^{* *}$ \\
\hline & $(0.780)$ & $(1.396)$ & $(1.500)$ & $(1.963)$ & $(1.058)$ & $(1.522)$ & $(0.282)$ & $(0.510)$ \\
\hline \multirow[t]{2}{*}{ POST $\times$ OTA-indep } & -0.768 & 1.387 & 0.426 & $-5.867 * * *$ & $-1.826^{*}$ & 0.755 & 0.369 & -0.0418 \\
\hline & $(0.803)$ & (1.384) & $(1.462)$ & $(1.930)$ & $(1.061)$ & $(1.617)$ & $(0.307)$ & $(0.468)$ \\
\hline \multirow[t]{2}{*}{$P O S T \times$ Dynamic } & 0.805 & $-3.102 * *$ & -0.660 & $4.109^{* *}$ & 1.082 & $-3.509 * *$ & $0.572 *$ & $0.978 * *$ \\
\hline & $(0.948)$ & $(1.517)$ & $(1.535)$ & $(1.849)$ & $(1.225)$ & $(1.635)$ & $(0.337)$ & $(0.463)$ \\
\hline Constant & $\begin{array}{c}24.66^{* * *} \\
(0.183)\end{array}$ & $\begin{array}{c}27.97 * * * \\
(0.287)\end{array}$ & $\begin{array}{c}57.19^{* * *} \\
(0.340)\end{array}$ & $\begin{array}{c}68.72 * * * \\
(0.388)\end{array}$ & $\begin{array}{c}55.47 * * * \\
(0.263)\end{array}$ & $\begin{array}{c}59.43 * * * \\
(0.382)\end{array}$ & $\begin{array}{c}16.44 * * * \\
(0.071)\end{array}$ & $\begin{array}{c}15.53 * * * \\
(0.100)\end{array}$ \\
\hline Observations & 55,387 & 24,760 & 55,387 & 24,760 & 55,387 & 24,760 & 55,387 & 24,760 \\
\hline$N$. of groups (hotels) & 677 & 301 & 677 & 301 & 677 & 301 & 677 & 301 \\
\hline$R$-squared & 0.869 & 0.877 & 0.708 & 0.763 & 0.892 & 0.886 & 0.950 & 0.964 \\
\hline
\end{tabular}

Fixed-effect regression, with each cross-sectional unit defined as a hotel

Robust standard errors in parentheses (clustered by hotels)

${ }^{(1)}$ POST is a dummy variable with value 1 when the online search date falls in the post-lockdown period, i.e. from $22 \mathrm{nd}$ March 2020

$\times$ denotes variables' interaction Coefficients highlighted in green (red) have the expected (opposed) sign and are significant (H2b)

$* * * p<0.01, * * p<0.05, * p<0.1$

supply (H2b). Considering a price-cost balance, it is reasonable to assume as a possible rational reaction of hotels the idea of posting prevalently rooms with free cancellation. More controversial is the implication of including breakfast and allowing more than 2 persons, as these options bear significantly higher costs in light of the need of satisfying social distancing rules. Table 4 presents the results, distinguishing as usual the cases of London and Munich, highlighting in green the significant effects going into the expected direction and in red the significant effects going in the other direction.

The number of variants reduces significantly at least in certain hotel categories, in particular, hotels belonging to chains and $4^{*}$ and $5^{*}$ hotels (though the latter effect is not significant in Munich). Thus, it seems that at least the most reactive hotel categories decided to rationalize their supply. For what concerns the share of free cancellation offers, there is a partial support to the hypothesis of an increase. In London, the effect spreads out over all categories, while in Munich the effect is more contrasting (for example, dynamic hotels increased the supply of free cancellation while OTA-independent ones decreased it). Again, in both cities, the effect is particularly strong for hotel chains.
The evidence becomes less clear when it comes to the share of breakfast. Only in London there is a significant general reduction $(-4.715, p<0.01)$. Despite the signs of the interaction with $4^{*}, 5^{*}$ and chains are all positive, it is necessary to calculate the value of the coefficient to the postlockdown effect to get the overall impact. Thus, the negative overall effect remains confirmed apart for $5^{*}$; it could be explained by a higher capability of reorganize the breakfast service, as well as better facilities making easier this task. Finally, no clear evidence emerges from the share of rooms targeted to more than 2 persons.

In sum, hotel tactical response to the pandemic proves to be very mixed, but some clear directions emerge in terms of both rooms and hotel characteristics affecting price and room variety supply. By looking at the whole picture, it seems that hotels in Munich were prompter to react in terms of price changes discriminating across room characteristics. Hotels in London have been less reactive in terms of price, but at the same time, they changed more proactively their room portfolio. Overall, this is consistent with $\mathrm{H} 2 \mathrm{~b}$; that is, the higher the effect of the pandemic, the stronger the need of hotels to change their booking tactics (in particular, free cancellation and breakfast) to cope with the crisis. 


\section{Conclusions and limitations}

Drawing from the resource-based view of the firm (Barney 1991) and from the crisis management theory (Booth 2015), this paper analyses how the hospitality industry coped with the COVID-19 pandemic. The increasing number of outbreaks and pandemics of the new century (Gössling et al. 2020) and the scarcity of hospitality crises management studies in the context of pandemics (Chen et al. 2020) make this paper relevant for theory and practice. COVID-19 represents a suitable setting to draw strategies that will support hoteliers in facing others health-related disasters (Hao et al. 2020). In Table 1, we presented an overview of strategies implemented by hoteliers to face crises and disasters. Generally, hotels reduce prices (Chen 2011), improve the service quality and cleanness of their hotels (Chien and Law 2003) and focus on the local/domestic demand (Henderson and $\mathrm{Ng}$ 2004; Page et al. 2006). Nevertheless, COVID-19 represents an unprecedented crisis event (Alonso et al. 2020; Gössling et al. 2020; Hao et al. 2020; Nicola et al. 2020; Sigala 2020) and our quasi-experimental approach allows to draw causal conclusions on the pre/post-strategies.

First, our study shows that a wider and flexible range of resources and capabilities is essential to promptly react to the pandemic. Structural condition last long (Barney 1991) and, to cope with a sudden and uncertain crisis, hoteliers should define a priori resources and capabilities necessary to promptly and effectively react against a crisis. In a recent study, Hao et al. (2020) show that in China, hotels equipped in advance to deal with a pandemic situation bounced forward the crisis earlier. To empirically test the role played by structural, managerial and tactical factors in coping with crisis, we used a rich dataset, highly representative of the heterogeneous universe of hotels in the two cities under analysis. Chain and dynamic hotels adjusted prices more. This could be explained considering an enhanced managerial approach to cope with the negative event. Specifically, chain hotels have the highest price discount than other hotels, which is made possible by their increased capacity to react quickly and in a cohesive fashion. Indeed, chain hotels improved their service quality by proactively creating a more focused portfolio of room offers that is better suited to meet the dire conditions that COVID made necessary. Due to their size, global presence and brand loyalty, chain hotels implemented timely proactive interventions by reducing prices as early as February 23 to limit losses. Indeed, if in a normal context dynamic pricing might hamper consumers' reference prices (Viglia et al. 2016), in case of a crisis, reducing prices mitigates economic losses and slightly improves the occupancy rate (Oaten et al. 2015).

Second, stemming from the dynamic approach of crisis management theory (Booth 2015) the paper shows the effectiveness of dynamic pricing and other booking tactics to deal with the crisis. In the study, we analysed two cities hit with different degrees of severity by the pandemic (i.e. Munich and London), as the crisis level is a relevant aspect to determine the right strategy bringing to a positive performance (Osiyevskyy et al. 2020). Results show differential approaches adopted by hoteliers in the two cities due to the pandemic contagion rates. The drastic drop in the demand determined by the pandemic makes hoteliers be prudent, exploiting less the potential of dynamic pricing and other booking tactics. This is the strategy pursued by London hoteliers that used less dynamic pricing and other booking tactics. Conversely, when the contagion rates decrease, hoteliers are freer to dynamically manage their offer. Our findings show a widespread use of dynamic pricing and other booking tactics by German hoteliers. These hotels appear therefore not to be concerned by the possible negative reputational effect that the application of an intensive price variability may induce (Seo 2019).

The multiple perspectives explored in the empirical analysis help to identify how structural and managerial resources, along with tactical strategies, may support hotels performance. Overall, our findings provide practical recommendations and managerial implications for hospitality operators. It is expected that in the next future pandemics might be more frequent and disruptive. Thus, operators should equip themselves in advance, to face the uncertain future as well as they possibly can. Accordingly, also hotels with a small number of resources and capabilities should structurally incorporate recovery strategies to cope with pandemics. Operators are called to acquire resources and capabilities a priori and organize them flexibly. Thus, for example, smaller operators may implement flexible contracts with employees and supplier with specific skills to make the access to resource dynamic. The so-called sharing economy suffered less than traditional markets because of a more flexible cost structure (Schaefers et al. 2021). Another relevant managerial implication for operators concerns the implementation of dynamic strategies along the contagion phases of the pandemic. When the pandemic is virulent and spread globally, operators should mitigate losses due to the drop in the demand. The flexible use of dynamic pricing and other booking tactics will lead to better performance.

This study provides an important first step in investigating hotels' recovery tactical strategies in the context of crises, disasters and pandemics. The work has some limitations. In what follows, we provide a future research agenda that can address such limitations. First, data were retrieved by a unique OTA (i.e. Booking.com). While Booking.com is the most used OTA in Europe (Stangl et al. 2016), it offers a partial picture. Secondly, it is premature to see the longterm performance-and image-effects of these actions. Thirdly, we show many hotels cut prices to cope with the 
crisis. However, future studies should include occupancy or RevPAR data to assess the impact of these structural, managerial and tactical levers. Future studies should also evaluate the overall impact of innovative booking tactics, such as hybrid meetings, hotel offices and all-inclusive room package, among others. Finally, although the evidence is often consistent across the two case studies, there are undoubtedly some important differences in findings emerging in London and Munich, in particular for what regards the specific applications of room price variants. These differences might be explained in light of the different severity of lockdown, but also specific characteristics of the tourism and hospitality sector in London and Munich cannot be ignored (such as, for example, the share of international travellers). Local vs. international guests' dependencies will certainly have differential effects for hotels, both in the short and in the long term. In fact, for cities and countries relying more on local guests, the sector will be more resilient, due to a lower amount of travelling restrictions.

\section{Declarations}

Conflict of interest We declare that no financial interest or benefit has arisen from the direct application of the research.

\section{References}

Abrate, G., and G. Viglia. 2016. Strategic and tactical price decisions in hotel revenue management. Tourism Management 55: 123-132.

Abrate, G., J.L. Nicolau, and G. Viglia. 2019. The impact of dynamic price variability on revenue maximization. Tourism Management 74: 224-233.

Alonso, A.D., S.K. Kok, A. Bressan, M. O'Shea, N. Sakellarios, A. Koresis, M.A. Buitrago-Solis, and L.J. Santoni. 2020. COVID19, aftermath, impacts, and hospitality firms: An international perspective. International Journal of Hospitality Management 91: 102654.

Anderson, R.M., H. Heesterbeek, D. Klinkenberg, and T.D. Hollingsworth. 2020. How will country-based mitigation measures influence the course of the COVID-19 epidemic? The Lancet 395 (10228): 931-934.

Barreda, A.A., S. Zubieta, H. Chen, M. Cassilha, and Y. Kageyama. 2017. Evaluating the impact of mega-sporting events on hotel pricing strategies: The case of the 2014 FIFA World Cup. Tourism Review 72 (2): 184-208.

Barney, J. 1991. Firm resources and sustained competitive advantage. Journal of Management 17 (1): 99-120.

Booth, S.A. 2015. Crisis management strategy: Competition and change in modern enterprises. Routledge.

Chen, M.H. 2011. The response of hotel performance to international tourism development and crisis events. International Journal of Hospitality Management 30 (1): 200-212.

Chen, C.C., Z. Schwartz, and P. Vargas. 2011. The search for the best deal: How hotel cancellation policies affect the search and booking decisions of deal-seeking customers. International Journal of Hospitality Management 30 (1): 129-135.
Chen, H., X. Huang, and Z. Li. 2020. A content analysis of Chinese news coverage on COVID-19 and tourism. Current Issues in Tourism: $1-8$.

Chien, G.C., and R. Law. 2003. The impact of the Severe Acute Respiratory Syndrome on hotels: A case study of Hong Kong. International Journal of Hospitality Management 22 (3): 327-332.

Cró, S., and A.M. Martins. 2017. Structural breaks in international tourism demand: Are they caused by crises or disasters? Tourism Management 63: 3-9.

Cross, R.G., J.A. Higbie, and D.Q. Cross. 2009. Revenue management's renaissance: A rebirth of the art and science of profitable revenue generation. Cornell Hospitality Quarterly 50 (1): 56-81.

Dahles, H., and T.P. Susilowati. 2015. Business resilience in times of growth and crisis. Annals of Tourism Research 51: 34-50.

del Mar Alonso-Almeida, M., and K. Bremser. 2013. Strategic responses of the Spanish hospitality sector to the financial crisis. International Journal of Hospitality Management 32: 141-148.

Dutta, S., M. Bergen, D. Levy, M. Ritson, and M. Zbaracki. 2002. Pricing as a strategic capability. MIT Sloan Management Review 43 (3): 61-66.

Dutta, S., M.J. Zbaracki, and M. Bergen. 2003. Pricing process as a capability: A resource-based perspective. Strategic Management Journal 24 (7): 615-630.

Fourie, J., and M. Santana-Gallego. 2011. The impact of megasport events on tourist arrivals. Tourism Management 32 (6): 1364-1370.

Giuffrida A., and L. Cochrane. 2020. 23rd February. Italy imposes draconian rules to stop spread of coronavirus. The Guardian. https:// www.theguardian.com/world/2020/feb/23/italy-draconian-measu res-effort-halt-coronavirus-outbreak-spread

Gössling, S., D. Scott, and C.M. Hall. 2020. Pandemics, tourism and global change: a rapid assessment of COVID-19. Journal of Sustainable Tourism: $1-20$.

Guizzardi, A., F.M.E. Pons, and E. Ranieri. 2017. Advance booking and hotel price variability online: Any opportunity for business customers? International Journal of Hospitality Management 64: $85-93$.

Hall. 2020. 30th April. Europe's biggest economies hone details on easing out of lockdown. Financial Times. https://www.ft.com/conte nt/abdb7223-06da-4d52-b380-5606628b5f0e

Han, E., M.M.J. Tan, E. Turk, D. Sridhar, G.M. Leung, K. Shibuya, et al. 2020. Lessons learnt from easing COVID-19 restrictions: An analysis of countries and regions in Asia Pacific and Europe. The Lancet. 396: 1525.

Hao, F., Q. Xiao, and K. Chon. 2020. COVID-19 and China's hotel industry: Impacts, a disaster management framework, and postpandemic agenda. International Journal of Hospitality Management 90: 102-636.

Haynes, N. 2016. The evolution of competitor data collection in the hotel industry and its application to revenue management and pricing. Journal of Revenue and Pricing Management 15 (3-4): 258-263.

Henderson, J.C., and A. Ng. 2004. Responding to crisis: Severe acute respiratory syndrome (SARS) and hotels in Singapore. International Journal of Tourism Research 6 (6): 411-419.

Hollenbeck, B. 2017. The economic advantages of chain organization. The RAND Journal of Economics 48 (4): 1103-1135.

Inversini, A., and L. Masiero. 2014. Selling rooms online: The use of social media and online travel agents. International Journal of Contemporary Hospitality Management 26 (2): 272-292.

Köseoglu, M.A., M. Altin, E. Chan, and O.F. Aladag. 2020. What are the key success factors for strategy formulation and implementation? Perspectives of managers in the hotel industry. International Journal of Hospitality Management 89: 102574. 
Makadok, R. 2001. Toward a synthesis of the resource-based and dynamic-capability views of rent creation. Strategic Management Journal 22 (5): 387-401.

Melis, G., and C.A. Piga. 2017. Are all online hotel prices created dynamic? An empirical assessment. International Journal of Hospitality Management 67: 163-173.

Mellinas, J.P. 2019. Dependency of Spanish urban hotels on Booking. com. Tourism Analysis 24 (1): 3-12.

Morrish, S.C., and R. Jones. 2020. Post-disaster business recovery: An entrepreneurial marketing perspective. Journal of Business Research 113: 83-92.

Nicola, M., Z. Alsafi, C. Sohrabi, A. Kerwan, A. Al-Jabir, C. Iosifidis, et al. 2020. The socio-economic implications of the coronavirus and COVID-19 pandemic: A review. International Journal of Surgery 78: 185-193.

Nicolaides, C., D. Avraam, L. Cueto-Felgueroso, M.C. Gonzalez, and R. Juanes. 2019. Hand-hygiene mitigation strategies against global disease spreading through the air transportation network. Risk Analysis 40 (4): 723-740.

Nicolini, M., and C.A. Piga. 2019. From uniform to bespoke prices: Hotel pricing during EURO 2016. SSRN. https://doi.org/10.2139/ ssrn.3314073.

Noone, B.M. 2016. Pricing for hotel revenue management: Evolution in an era of price transparency. Journal of Revenue and Pricing Management 15 (3-4): 264-269.

Oaten, S., K. Le Quesne, and H. Segal. 2015. Adapting to Uncertainty-The Global Hotel Industry. In World Economic Forum. Geneva: Travel and Tourism Competitive Report.

Osiyevskyy, O., G. Shirokova, and P. Ritala. 2020. Exploration and exploitation in crisis environment: Implications for level and variability of firm performance. Journal of Business Research 114: 227-239.

Page, S., I. Yeoman, C. Munro, J. Connell, and L. Walker. 2006. A case study of best practice-Visit Scotland's prepared response to an influenza pandemic. Tourism Management 27 (3): 361-393.

Paraskevas, A., L. Altinay, J. McLean, and C. Cooper. 2013. Crisis knowledge in tourism: Types, flows and governance. Annals of Tourism Research 41: 130-152.

Parnell, D., P. Widdop, A. Bond, and R. Wilson. 2020. COVID-19, networks and sport. Managing Sport and Leisure 1-7.

Pohland, L., and M. Kesgin. 2018. Pricing determinants in hotels: The case of luxury, upscale, and mid-scale price segments. Journal of Revenue and Pricing Management 17 (4): 218-230.

Ritchie, B.W., and Y. Jiang. 2019. A review of research on tourism risk, crisis and disaster management: Launching the annals of tourism research curated collection on tourism risk, crisis and disaster management. Annals of Tourism Research 79: 102812.

Schaefers, T., G. Narayanamurthy, R. Moser, and M. Leban. 2021. The sharing economy at the base of the economic pyramid: How access-based services can help overcome ownership risks. Psychology \& Marketing. 38: 2073.

Seo, K. 2019. Same-day discounting's effect on consumers' evaluations of a hotel. Journal of Revenue and Pricing Management 18 (2): 107-111.

Sigala, M. 2020. Tourism and COVID-19: Impacts and implications for advancing and resetting industry and research. Journal of Business Research 117: 312-321.

Revilla-Camacho, M.Á., B. Palacios-Florencio, D. Garzón, and C. Prado-Román. 2020. Marketing capabilities and innovation. How do they affect the financial results of hotels? Psychology \& Marketing 37 (3): 506-518.
Stangl, B., A. Inversini, and R. Schegg. 2016. Hotels' dependency on online intermediaries and their chosen distribution channel portfolios: Three country insights. International Journal of Hospitality Management 52: 87-96.

Statista. 2020. Potential loss of revenue for UEFA for postponing or cancelling Euro 2020 due to the coronavirus (COVID-19) pandemic as of March 2020. https://www.statista.com/statistics/11056 19/covid-euro-2020-revenue-loss/ Accessed 02 June 2020

Sun, Y.Y., A. Rodriguez, J.H. Wu, and S.T. Chuang. 2013. Why hotel rooms were not full during a hallmark sporting event: The 2009 World Games experience. Tourism Management 36: 469-479.

Tew, P.J., Z. Lu, G. Tolomiczenko, and J. Gellatly. 2008. SARS: Lessons in strategic planning for hoteliers and destination marketers. International Journal of Contemporary Hospitality Management 20 (3): 332-346.

Viglia, G., A. Mauri, and M. Carricano. 2016. The exploration of hotel reference prices under dynamic pricing scenarios and different forms of competition. International Journal of Hospitality Management 52: 46-55.

Ye, B.H., A.A. Barreda, F. Okumus, and K. Nusair. 2019. Website interactivity and brand development of online travel agencies in China: The moderating role of age. Journal of Business Research 99: 382-389.

Zeng, B., R.W. Carter, and T. De Lacy. 2005. Short-term perturbations and tourism effects: The case of SARS in China. Current Issues in Tourism 8 (4): 306-322.

Publisher's Note Springer Nature remains neutral with regard to jurisdictional claims in published maps and institutional affiliations.

Claudio A. Piga is Full Professor of Economics at the University of Genova (Department of Economics, Via Vivaldi 26, 16126 Genova, Italy. Email: claudio.piga@unige.it). His research interests cover a number of areas in applied microeconomics: pricing, with a particular focus on the airline and the travel and tourism industry, policy evaluation and relevant econometric techniques.

Graziano Abrate is Associate Professor of Management at the University of Piemonte Orientale (Department of Economics and Business, Via Perrone 18, 28100 Novara, Italy. Email: graziano.abrate@uniupo. it). His research interests include pricing and revenue management, demand estimation and efficiency analysis, with a particular focus on the tourism and hospitality sector. (* Corresponding Author)

Giampaolo Viglia is Full Professor of Marketing at the University of Portsmouth (Department of Marketing, Richmond Building Portland Street, Portsmouth, PO1 3DE, United Kingdom. Email: giampaolo. viglia@port.ac.uk) and at the University of Valle d'Aosta (Department of Economics and Political Sciences, Località Le Grand-Chemin 181, 11020 Saint-Christophe, AO, Italy). His research interests focus on consumer behaviour, pricing strategies and marketing of tourism services.

Francesca De Canio is a Post-Doc Research Fellow at the University of Modena and Reggio Emilia (Department of Economics Marco Biagi, Viale Berengario 51, 41124 Modena, Italy. Email: francesca.decanio@ unimore.it). Her research interests focus on consumer behaviour within a retail environment, with a focus on online retailing. 